The second session was devoted to more detailed treatments of-chiefly high-resolution-nuclear magnetic resonance in various branches of chemistry. Dr. J. A. S. Smith (University of Leeds) opened his review of inorganic applications with a reference to susceptibility measurements of liquids by nuclear magnetic resonance, as first suggested by Feher and Knight and more recently by Frei and Bernstein ${ }^{4}$, a topic which attracted attention in the subsequent discussion with regard to the validity of the calculations to samplos in close contact. A variety of problems, including general stereochemistry, detailed bonding, and exchange processes, was described, starting with hydrido-complexes in which direct hydrogen-1-metal bonds are characterized by a proton peak of vory high $\tau$-value. The metal alkyls exemplify the use of both of the commonly measured nuclear magnetic resonance high-resolution parameters: coupling of the magnetic platinum-195 nucleus in aqueous trimethylplatinum nitrate ${ }^{5}$, for example, gives a $77 \cdot 3-\mathrm{c} / \mathrm{s}$ doublet across the methyl singlet corresponding to platinum nuclei with zero spin; while chemical shifts between methylene and methyl protons in $X-\mathrm{CH}_{2}-\mathrm{CH}_{3}$ compounds have been correlated with electronegativity. Among $\pi$-complexes, such as Zeise's salt and cyclopentadienyl complexes, Dr. Smith showed that a comparatively simple hydrogon-1 resonance criterion can sometimes give a useful structural indication. Most of the talk dealt with diamagnetics, but mention was made of some paramagnetic complexes in solution, for example, the nickel (II) aminotroponeimineates, in which the relaxation times pormit quite wellresolved high-resolution hydrogen-1 spectra to be recorded, from which spin densities have been deduced ${ }^{6}$.

Speaking about applications to organic structure determination, Dr. A. R. Katritzky (University of Cambridge; professor designate, University of East Anglia) first showed how phosphorus-31 resonance in monothiopyrophosphates can give a simple proof of the symmetry of a product. He then concentrated on hydrogen resonance in a limited range of nitrogen heterocyclic compounds of fairly low molecular woight, starting with the information that $\tau$-values and multiplicities can givo about disulphonylaminopyridines. Dr. Katritzky directed attention to the effects of tautomeric rates on nuclear magnetic resonance spectra and to the importance of interpreting these spectra in conjunction with those from the infra-red and ultra-violet, instancing 3,4-dimethyl- $\Delta^{3}$ pyrrol-2-one and related compounds ${ }^{7}$ Finally, Dr. Katritzky showed how the rapid molecular rearrangement of benzofuroxan manifests itself in proton resonance as a change from an unsymmetrical $A B C D$ spectrum at low temperatures to a symmotrical $A_{2} B_{2}$ spectrum at $130^{\circ} \mathrm{C}$ (ref. 8).

Polymers have been investigated by both broad-line and high-resolution nuclear magnetic resonance tech- niques. Dr. I. M. Ward (Imperial Chemical Industries, Ltd., Fibres Division) first discussod the measurement over a temperature range of the width, second moment, and relaxation times of comparatively broad polymer lines, which can often lead to information about the motion of tho structure and to a nuclear magnetic resonance parameter related to crystallinity. A molecular interpretation of the nuclear magnetic resonance transitions tends to be more readily obtained for the main glass transition than for processes at lower temperatures. With polypropylene as an example $\theta^{9}$, the advantages of making measurements on a number of deuterated samples and of correlating nuclear magnotic resonance and dynamic mechanical data were outlined. The same polymer was used to illustrate the desirability of being able to interpret high-resolution spectra of polymors in solution in terms of local stereochemistry and so predict stereoregularity in tho bulk of the polymer. However, undeuterated vinyl polymers are liable to give overlapping spectra complicated by coupling from protons on the $\alpha$-carbon ${ }^{10}$; most published nuclear magnetic resonance investigations of stereoregularity havo been on more amenable polymers, such as polymethyl methacrylate or deuterated polypropylene.

In the concluding session, several manufacturers described the potentialities of commercial nuclear magnetic resonance spectrometers. Mr. J. M. Babb (Varian AG) outlinod equipments extending from a $2-16 . \mathrm{Mc} / \mathrm{s}$ variable frequency broad-line instrument through the $60-\mathrm{Mc} / \mathrm{s}$ analytical spectrometer to the $100-\mathrm{Mc} / \mathrm{s}$ system; Dr. I. Stelzer (Delviljem, Ltd.) presented the less-familiar but almost equally extensive Japan Electron Optics range; and Mr. H. J. M. Fitches (Associatod Electrical Industries, Ltd.) discussed a British spectrometer based on a 14,000 gauss electromagnet and capable of resonating at various frequencies. Among permanent magnet high-resolution spectromoters, Mr. L. Minikin (Mullard Equipment, Ltd.) described a relatively cheap 9,000 gauss instrument intended for proton resonance, and Mr. L. K. Parker (Perkin-Elmor, Ltd.) introduced a 14,000 gauss instrument designed to operate at the frequencies of several nuclei either separately or for spin decoupling. D. W. Jones

1 Shoolery, J. N., Disc. Faraday Soc., 34, 104 (1962).

2 Baldeschwieler, J. D., and Randall, E. W., Chem. Revs., 68, 81 (1963).

3 Freeman, R., and whiffen, D. H., Proc. Phys. Soc., 79, 794 (1962).

4 "Frei, K., and Bernstein, H. J., J.'Chem. Phys., 37, 1891 (1962).

${ }^{5}$ Smith, J. A. S., J. Chem. Soc., 4736 (1962).

'Eaton, D. R., Josey, A. D., Phillips, W. D., and Yenson, R. E., Disc. Farad. Soc., 34, 74 (1962).

'Pleininger, H., Bauer, H., Katritzky, A. R., and Lerch, U., Annalen, 654, 165 (1962).

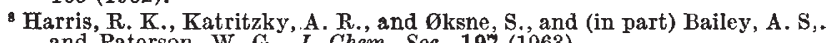
and Paterson, W. G., J. Chem. Soc., 197 (1963).

- MeDonald, M. P., and Ward, I. M., Proc. Phys. Soc., 80, 1249 (1962).

${ }^{10}$ Tincher, W. C., Amer. Chem. Soc., Division of Polymer Chemistry, rarers presented at Atlantic City meeting, 3, No. 2, A142 (1962).

\title{
SHRINKPROOFING WOOL
}

A COLLOQUIUM on shrinkproofing sponsored by the Commonwealth Scientific and Industrial Research Organization and the University of New South Wales was held on March 13 at the Organization's Division of Textile Physics, Sydney. This was the third in the series of wool research colloquia which the C.S.I.R.O. initiated in 1961; the first two dealt with the structure of wool and the setting of wool respectively. Prof. J. B. Speakman, of the University of Leeds, gave the opening address. Only three formal papers were presented and, in addition to discussion periods associated with the papers, an entire session was reserved for informal contributions from the sixty invited delegates.

Prof. Speakman dealt with the three main methods of obtaining shrink-resistance in wool fabrics-cross-linking, resin deposition and chemical degradation. He pointed out that the last method, the most commonly used, was least satisfactory in its effect on other important fabric properties such as resistance to wear. No major advance had been made in the theoretical understanding of this approach in the twenty-five years since the suggestion was put forward that the only necessary reaction was rupture of disulphide bonds. The optimum result was obtained when this reaction was confined as much as possible to the surface layers of the fibres, to produce modification of the scales. Recently, processes of this type had been adapted for continuous treatment combined with continuous dyeing.

The other approach to surface modification was to mask the scales by dopositing resin. Such a treatment could be used to improve resistance to wear and resistance to 
creasing of wool fabrics at the same time as it conferred shrink-resistance. Combined in the one process, these effects would enable development of easy-care tropical worsted fabrics. For a given weight of polymer, the optimum benefits in both shrink-resistance and abrasionresistance would be obtained only if the resin were polymerized by a method which at the same time anchored it chemically to the fibres.

Prof. Speakman suggested that cross-linking had the greatest potential as a shrinkproofing technique. No industrial process of this type had been developed, and this was due to lack of knowledge of the distribution of the reactive sido-chains in keratin. Moreover, in past investigations insufficient attention had boen given to the ratio of the amount of cross-linking reagent to the amount of wool. Unless this was strictly controlled, optimum cross-linking might not be obtained. If these problems were overcome, a process could be developed which would bo satisfactory for all end-uses except those requiring crease-resistance.

Dr. E. F. Denby and Dr. M. W. Andrews (C.S.I.R.O.) reported progress in analysing fibre movement during washing of untreated fabric and fabric shrinkproofed with the C.S.I.R.O. potassium permanganate/saturated sodium chloride process. They claimed that the direct effect of washing was fibre movement and showed that the treatment caused a reduction in the rate of fibre movement. For a given level of treatment this rate was constant up to at least 10 per cent linear shrinkage. Thus there was considerable fibre movement during the induction period (the period at the commencement of washing when no shrinkage occurs). The relation between shrinkage and the average fibre movement was independent of the level of the treatment. This indicated that the mechanism of felting was the same in the treated and untreated fabrics.

The force required to move the fibres during washing depended on their elastic properties, their frictional properties and the distribution and pressure of inter-fibre contacts. Average values of this force were obtained by pulling fibres from the fabric in the against-scale and withscale directions. The against-scale force for the treated fabric was considerably less than the value for the untreated fabric, whereas the with-scale force was only slightly altered by the treatment. The force was also altered by washing the fabric. A significant increase in the against-scale force occurred during the induction period. It was suggested that this increase was due to changes in the surface of the fibres brought about by the mechanical effect of the washing, and that an increase in the with-scale force, which was observed at the end of the induction period, might be associated with the formation of 'entanglements' of the type suggested by Shorter.

Developments and progress in shrinkproofing were reviewed by Dr. J. R. McPhee (C.S.I.R.O.). He suggested that research into the chemical degradation methods should be directed towards making simpler and cheaper processes, keoping in mind the disadvantages that still existed in processes of this bype. Although resin treatments appeared to offer genuine advantages, these advantages tendad to be outweighed in practice because the cost and complexity were high. The most promising was the formation of polyamides on the fibre surface by $a$ technique called 'intorfacial polymerization'.

The informal discussion prriod was led by Prof. A. Datyner (University of Now South Wales) and Dr. A. J. Farnworth (Australian Wool Bureau), who briefly discussed problems and anomalies encountered in shrinkproofing research. The main impression gained from this discussion period was of wide gaps in basic knowledge. At present many phenomena have not been explained, and in some cases sound basic ideas have not beon devoloped to the stage required for industrial use. Dr. Farnworth listed soveral instances; for example, the efficiency of the simple oxidation processes would be considerably increased if the reaction could be restricted entirely to those chemical sites the modification of which is essential for changes in the frictional properties of the fibres; however, little is known about these sites. Delegates reported that the effoct of surface contaminants on the efficiency of many processes is not fully understood; nor did they know how to explain the pattern in which $p H$, temperature, otc., of the felting media affect felting rates. Above all, there is very little information about what happens physically in a fabric during felting.

To conclude on this note would be to deny the sound progress made in this field. The manufacturer has now come to a realistic appreciation of the need for careful quality control. Dr. MePhee reported that there are at least six processes in common use producing good results for a wide variety of applications; several of thoso processes do not impair the 'handle' of the wool. Thus the textile chemist has disdained the luxury of inactively waiting for basic research to point the way to the process ne plus ultra.

E. F. DENBY

M. W. ANDREWS

\section{ENERGY AND THE EUROPEAN ECONOMIC COMMUNITY}

\begin{abstract}
A BROADSHEET written by J. Hartshorn, entitled An Energy Policy for E.E.C., and issued by Political and Economic Planning*, reviews briefly the national energy policies of Belgium, France, Western Germany, Italy, Luxembourg, the Netherlands and the United Kingdom, the search of the European Economic Community for a co-ordinated energy policy up to the 1962 proposals for a common market in energy, and finally considers the prospects for a policy.

While during the past three years the concepts on which a logical and coherent policy might be based have been steadily refined, there is no certainty that the member nations can be brought to accept one. Nobody, even coal interests, expects to be able to expand domestic fuel-producing capacity and productivity enough to keep pace with the growth of energy requirements to the extent that, for example, European farm interests can con-
\end{abstract}

* Planning, Vol, 29. No. 469 (18th March, 1963). An Energy Policy for E.E.C. By Jack Hartshorn. Pp. 55-98. (London: Political and Economic fidently be hoped to expand in domestic farm products. Energy demand per head shows less sign of levelling off within rising standards of living than food demand does.

The French have some objections of principle to the concept of an open common market in energy, and are not convinced that this is the surest way of arriving at the lowest energy costs if that means giving the nonEuropean oil companies free play at a time when the Community's energy resources are on the point of being used up. Reliance on the diversification of sources of oil supply is a real safeguard, but its importanco can be exaggerated. Diversification may raise the question of possible preference to particular oil-producing areas. In the context of scarcity, the 4-6 month level of supplies suggested for stocks by the European Economic Community has much logic, but may not be cheap even if it supplies sufficient insurance against the interruption of Soviet supplies as well.

Apart from the vested interests of the European nations concerned, Mr. Hartshorn sees cogent arguments for delay, and points out that it is difficult not to share some 